\title{
Politizar en contextos "poco politizados" Paradojas y tensiones en torno al desarrollo del poder de actuar en centros sociales franceses
}

\section{(4) Catherine Neveu}

IIAC-LACI (CNRS-EHESS), París, Francia

ORCID iD: 0000-0001-6480-5885

Correo electrónico: catherine.neveu@ehess.fr doi: $10.34096 /$ cas.i50.7028

\section{Palabras clave}

Poder de actuar; Politización; Centros sociales; Capacitación; Competencias cívicas

\section{To politicize in "not very politicized" contexts: paradoxes and tension regarding the development of the power to act in French social centers}

\begin{abstract}
Through an analysis of training practices, this article explores the circulation and appropriation of the notion of "empowerment" as a potential opportunity to politicize discourses, actors and practices in French social centers. The diffusion of this category actualizes a series of structural tensions in the social centers network between on the one hand, an aim of emancipation and social transformation, and on the other hand a set of representations about the political role of social centers. Through and beyond these tensions, the article questions contemporary modes of "political training" of actors when democracy is more thought of as acting than as an issue of abstract training.
\end{abstract}

\section{Key words}

Empowerment; Politicization; Social centers; Training; Civic competences 
Palavras-chave

Poder de atuar; Politização; Centros sociais ; Capacitação; Competências cívicas
1. Le pouvoir d'agir es la traducción más común utilizada en francés de la palabra "empoderamiento"

o "empowerment". Considero preferible utilizar aquí la palabra vernácula, es decir "el poder de actuar" y no el equivalente usual en español (empoderamiento).

\section{Politizar em contextos "pouco politizados": paradoxos e tensões ao derredor do desenvolvimento do poder agir em centros sociais franceses}

\section{Resumo}

Este artigo interroga as maneiras de circulação e apropriação de um meio de politização (dos discursos, atores e práticas) difundidas na rede dos centros sociais na França nos últimos anos, a do desenvolvimento do "poder de agir" dos e das habitantes, através da analise das práticas de capacitação. A circulação desta noção atualiza um conjunto de tensões de longa data e quase estruturais na história da rede entre, por una parte, o desejo de emancipação e transformação social e, pelo outro, um conjunto de representações vigentes ao redor do papel político dos centros sociais. Para além destas tensões, a analise abre uma pergunta central em relaçao as modalidades contemporâneas da "formação política" dos atores, numa época da "democracia do fazer".

\section{Introducción}

A pesar de ser casi centenaria, la red de los centros sociales en Francia sigue siendo una institución muy poco visible para la investigación sobre los procesos de politización. En relación con el mundo asociativo, esta investigación se ha interesado a las modalidades de compromiso en asociaciones temáticas (medioambientales, de barrio; véase Lagroye, 2003; Hamidi, 2006; Guionnet, 2013) o a los procesos de "politización ordinaria" (Carrel, 2017), sin que los centros sociales aparecieran como espacios relevantes. Con la intención de llenar este vacío en los estudios sobre los procesos de politización, la investigación sobre la cual se basa este artículo tiene como objetivo entender cómo la politicidad se expresa en estos espacios, los centros sociales, que, si bien persiguen un objetivo de transformación social, no lo muestran explícitamente en la cotidianidad de sus actividades. Así, los y las que participan en estas actividades no están necesariamente motivados/as por una voluntad de comprometerse o de "cambiar el mundo". Resulta entonces interesante entender mejor cómo se desarrollan, en este caso, las formas de politización en la rutina ordinaria de las prácticas y relaciones.

Algunos aspectos de los vínculos entre sociabilidad ordinaria y politicidad ya han sido analizados en estudios previos (Neveu, 2016). Este artículo interroga las modalidades de circulación y de apropiación de un medio de politización (de los discursos, actores y prácticas) difundidas en la red de los centros sociales en los últimos años, la del desarrollo del "poder de actuar" de los y las habitantes, a partir del análisis de las prácticas de formación/capacitación orientadas al "desarrollo del poder de actuar" (DPA) que se proponen en los centros sociales (cursos de formación para empleados/ as, miembros de consejos de administración o voluntarios/as).

Los centros sociales en Francia son espacios establecidos en barrios populares. Nacieron hace casi 100 años, a partir de la conjunción de movimientos filantrópicos de inspiración cristiana y movimientos de la "educación popular", en busca de la emancipación de las clases populares (Durand, 1996). La gran mayoría de los centros sociales hoy tienen un estatuto de asociación, lo que generalmente implica su autonomía en la definición de su proyecto social. Pero hay que señalar que de modo paulatino se convirtieron prácticamente en subcontratistas o proveedores de políticas públicas sociales (ver más adelante). Hoy en día, el $80 \%$ de los recursos de los centros sociales proceden de fondos atribuidos por instituciones públicas y locales. 
Es precisamente debido a tal evolución desde los años 1970-1980 que la Federación Nacional de los Centros Sociales (FCSF, por su denominación en francés) decidió, al inicio de los años 2010, poner en marcha una estrategia de "repolitización" de las prácticas, actores y discursos basada en la noción de "desarrollo del poder de actuar" de los y las habitantes, con el objetivo de recuperar la capacidad de intervención en el espacio público y de transformación social. ${ }^{2}$

De hecho, la medida del DPA actualiza un conjunto de tensiones de larga data y casi estructurales en la historia de la red entre, por un lado, el deseo de emancipación y transformación social y, por otro lado, un conjunto de representaciones vigentes en torno al papel político de los centros sociales, ya sea en las relaciones que se establecen con las instituciones públicas relativas a la cuestión de la conflictividad social, o bien respecto de las competencias cívicas (Talpin, 2010) de los/las habitantes. Estas dimensiones han sido consideradas por la literatura académica como centrales para identificar procesos de politización (Lagroye, 2003; Arnaud y Guionnet, 2005; Hamidi, 2006; Bacqué y Biewener, 2013). El análisis de las prácticas de formación sobre el poder de actuar puede ser entonces un punto de partida pertinente para entender mejor tanto la implementación de esta estrategia como los obstáculos que se pueden encontrar. La puesta en circulación, por medio de estas formaciones, de una categoría politizada o "politizable"3 (la de poder de actuar) pone en tensión las costumbres y rutinas de un contexto local poco politizado. De hecho, no existe en los centros sociales de la Región Centre Val de Loire la idea de que estos constituyen espacios políticos, ámbitos de movilización o de transformación social. La gran mayoría de los socios/as y empleados/ as no tiene una representación de su papel y del de los centros como político ni una trayectoria previa de compromiso social o político. No obstante, en una diversidad de espacios y ocasiones, se expresan en estos centros sociales formas de "politicidad".

Propongo usar la palabra 'politicidad' en el mismo sentido que en sociología se usan las nociones de 'sociabilidad' o de 'cultura' popular. Esto permite salir de una posición de exterioridad en la cual suele ubicarse a las clases populares cuando hablamos del 'vínculo a la política', como si lo político fuera una substancia o un universo exterior. Exterior al mismo tiempo a su identidad y a sus prácticas, con el cual los individuos se encontraran 'después'. (Merklen, 2006, p. 191)

Según Denis Merklen, la politicidad designa "cualquier testimonio de la condición política de los seres en sociedad, independientemente de la forma que esta actividad adopta. Esta politicidad desemboca en la realización de nuevas formas autónomas de compromiso y de acción" (Merklen, 2012, p. 103). Dichas formas podrían ser puntos de apoyo para un trabajo de (re)politización; analizar por qué no están aprovechadas en los centros sociales de la Región Centre Val de Loire arroja luz sobre las representaciones de lo político, así como de las "competencias" de los/as habitantes.

Se trata entonces de entender más las paradojas derivadas de la puesta en circulación de esta categoría politizada a partir de un conjunto de espacios de capacitación, que los efectos mismos de la politización. Seguir la noción de "poder de actuar" (Marcus, 1995) en diferentes espacios y niveles, analizar sus recepciones y usos variables y cómo pone en tensión prácticas establecidas, constituye una herramienta fructífera para entender los modos en que los mismos actores logran - o no- pensar en tanto "políticas" las preguntas que surgen o los objetivos que se fijan. El enfoque sobre las prácticas de capacitación dedicadas al poder de actuar, por su parte, permite abrir la discusión sobre los desafíos de una visión "pedagógica" de la democracia y de la politización.
2. Iniciada en 2013, la investigación se desarrolla, entre otros, en un centro social en los alrededores de Tours, en una ciudad de 37.000 habitantes, y un barrio donde más de la mitad de los alojamientos son casas individuales de los años 1960-70, y el resto, viviendas sociales. Además de un trabajo de campo que se prolongó durante dos años (2013-15) y fue retomado en 2017 en el marco de un proyecto colectivo “'L'engagement et la participation au prisme du pouvoir d'agir" ("El compromiso y la participación bajo el prisma del poder de actuar”, ENGAGIR por su denominación en frances), la investigación también incluye otros espacios de indagación a nivel departamental, regional o nacional, así como el análisis de documentos producidos por la red y la FCSF. El proyecto ENGAGIR, La participation et l'engagement au prisme du pouvoir d'agir (financiado por la Región Centre Val de Loire) reúne a diez investigadoras de las Universidades de Tours y Orléans, y la Federación Regional de los Centros sociales Centre Val de Loire. Se trata de un proyecto colaborativo cuyas líneas de investigación fueron definidas en conjunto y que incluye talleres de coproducción del análisis de las prácticas y representaciones.

3. Politizada o politizable en el sentido de que la categoría de poder de actuar se refiere a dos dimensiones centrales de la politización: la conflictualización y el movimiento del particular al universal. 


\section{Una categoría que actualiza tensiones de larga data}

Antes de presentar los elementos de análisis desde la investigación empírica, es necesario plantear el contexto en que la estrategia de DPA funciona, así como localizar el paisaje más amplio de la historia de los centros sociales. El tema del rol político que estos espacios ocupan constituye un debate recurrente en la historia de la red, desde su origen en corrientes filosóficas caritativas de inspiración católica y en otras inspiraciones cercanas del pensamiento de la emancipación y de la educación popular (Durand, 1996; Maguin, 2004). A raíz de los settlements nacidos en Londres al fin del siglo XIX, los centros sociales se desarrollaron en Francia a partir de una voluntad de "hacer obra social, y no obra caritativa, es decir establecer en los lugares de vida, vínculos de cooperación emancipadora entre personas de condiciones sociales y económicas diferentes" (Mémoires Vives, 2016). Aunque no resulta posible aquí reconstruir la historia compleja de la red, según Maguin, se puede señalar que, después de un periodo "feliz" de desarrollo y apropiación por los habitantes de barrios populares (1946-1982), que comienza al inicio de los años 1980, se observa

la multiplicación de pedidos institucionales sectoriales dirigidos a poblaciones destinarias [...]. Frente a las necesidades urgentes de las poblaciones, privadas de los/as militantes que permitieron en los años 50-70 desarrollar una visión global de la sociedad y la promoción de los sectores populares, los centros sociales retomaron políticas institucionales a veces asistenciales, con el riesgo de perder su identidad y especificidad en el campo de la acción social. (Maguin, 2004, p. 21)

En respuesta a este cambio, así como a la profundización de la crisis social, económica y democrática, la red se comprometió, a partir de los años 2010, a una transformación profunda. La Universidad Federal de la FCSF marcó un hito importante en 2011. Al restituir su trabajo, en un documento propuso "abrir el diálogo, descubrir la complejidad de los desafíos sociales contemporáneos, identificar desacuerdos y convergencias, suscitar el deseo de actuar descubriendo instrumentos de acción y nuestra capacidad de colectivamente imaginar soluciones" (FCSF, 2012). Referirse a la noción de DPA fue entonces la traducción de una voluntad fuerte de reconquistar un rol político y una palabra frente a la paradoja de localizarse entre un "requerimiento de paz social" (procedente de los financiadores) y un objetivo de emancipación. Tal estrategia de repolitización de las acciones y de los actores tenía como uno de sus ejes centrales la redefinición de la articulación entre aproximación individualizada y acción colectiva, como una reapertura de "lo posible":

la identificación de las necesidades de los habitantes y la valorización de su potencial (más que la recuperación de sus carencias) ya constituía una acción de los Centros sociales. Pero promover la organización colectiva es algo diferente [...] se necesita una evolución más intencional. (Passer de la participation au pouvoir d'agir, c'est nécessaire, c'est possible, documento preparatorio para el Congreso 2013, Consejo de Administración [CA] FCSF, enero 2013. Énfasis de la autora)

4. La noción se deriva del enfoque cognitivo sobre políticas públicas que desarrolló Pierre Muller. Según este autor, elaborar una política pública consiste en construir una representación, una imagen de la realidad sobre la cual se quiere actuar. Los actores organizan su percepción del problema y definen sus acciones con base en esta imagen cognitiva. Tal visión del mundo se encuentra en el "référentiel" de una política pública. Ver Muller (2013).
Desde la primera mitad de la década de 2010, se observa entonces una voluntad explícita de reconquistar un papel político de apoyo a acciones de transformación social que tiene por objeto "liberar las capacidades de imaginación y acción de la sociedad civil" y afirma que "existen relatos de dominación y de desigualdad social, contra los cuales queremos contribuir a luchar desarrollando el poder de actuar de los habitantes" (FCSF, 2014, p. 8).

Esta orientación es notable por su voluntarismo, sin embargo, reactualiza también debates mucho más antiguos en la red de los centros sociales. Régis Cortesero (2013) destacó al menos cuatro "référentiels" ${ }^{4}$ que funcionan históricamente en los centros sociales: el 
de la integración, que valoriza la unidad social y la estabilidad; el de la cohesión social, muy presente en la aproximación institucional; el de la individuación, que valoriza al individuo y su cumplimiento personal; y el del equilibrio conflictual, que valoriza el conflicto y la emancipación colectiva a partir de la acción. Según este autor, cada uno de estos référentiels define a los centros sociales como actores políticos en términos específicos. Según el référentiel de la integración, interviene en la formación de un "ciudadano informado", es decir, aquel que tiene conocimiento sobre cómo funcionan las instituciones, cuáles son sus derechos, etc.; el de la cohesión social estimula el compromiso social de los individuos especialmente en prácticas de deliberación. En el caso del référentiel de la individuación, este estimula y organiza la solidaridad humana entre individuos mediante relatos de reconocimiento y oportunidades. En el último caso, facilita la confrontación de intereses al ayudar a los grupos dominados a acceder a la palabra y la representación (Cortesero, 2013).

Observar las prácticas de formación constituye un punto de partida pertinente para aprovechar la actualidad de esta diversidad de concepciones y las tensiones que surgen en relación con la puesta en circulación de la noción de "poder de actuar". De hecho, precisamente debido a la falta de "tradición" política o de compromiso social dentro de los consejos de administración o entre los voluntarios/as y empleados/as en los centros sociales de la región Centre Val de Loire (a diferencia de otras regiones), el référentiel del equilibrio conflictual casi no se encuentra. Por el contrario, domina otra tradición de algunas corrientes de la educación popular y del trabajo social: la de la evasión del conflicto o, al menos, de una relación compleja con la conflictividad social. ${ }^{5}$ El trabajo de politización resulta entonces demasiado difícil, tal como describiremos a continuación.

\section{Una diversidad de concepciones poco discutida}

Una primera observación posible, es que las formaciones ${ }^{6}$ reflejan la diversidad de concepciones del "poder de actuar" disponibles en la literatura. Marie-Hélène Bacqué y Carole Biewener (2013) destacaron las diferencias entre varias de sus definiciones y aproximaciones, por ejemplo, en la importancia respectiva de las dimensiones individuales o colectivas de la emancipación. Por su lado, la FCSF se basó principalmente en la concepción promovida por un psicólogo quebequés (Yann Le Bossé), para quien el poder de actuar es "en el sentido amplio, la capacidad para las personas de controlar lo que es importante para ellas, sus familiares, la colectividad con la cual se identifican" (FCSF, 2014, pp. 34-35).

Como ilustración de esta diversidad, se puede tomar el ejemplo de una formación en un centro social de la aglomeración de Tours en 2014 dirigida por María, una empleada que tenía un recorrido profesional como trabajadora social. Su visión sobre el poder de actuar, muy cercana al référentiel de la individuación, se basaba en una aproximación desde la emancipación individual y una visión propedéutica de la participación según la cual "la participación es un preámbulo al poder de actuar: hay que participar mucho tiempo y solo después se puede desarrollar su poder de actuar" (María, sesión de formación, Centro social del Bosque Rojo, ${ }^{7}$ marzo 2014). Para ella, el "poder de actuar" se relaciona principalmente con un conjunto de competencias que deben adquirir los individuos. La estrategia que propuso, entonces, fue la de identificar determinadas "personas recursos" en el barrio, a quienes se podría proponer un tipo de coaching individual para que aprendieran a hablar en público. Por su parte, la cuestión de la acción colectiva parecía mínima: "se trata de personas que, si les consideramos solas, tienen ideas y conocimientos, ¿ ¿sí? Pero después hay que tener en cuenta [si entran] en un grupo, va a ser... j'caliente!"' (María, sesión de formación, Centro social del Bosque Rojo, marzo 2014).
5. Concepción que surge del enfoque "anticlasista" de corrientes del catolicismo social, que privilegian la cooperación entre las clases sociales; véase (Dessertine, Durand, Eloy, Gardet, Marec y Tétard, 2004).

6. Se trata de formaciones para empleados/as, voluntarios/ as o socios/as de los consejos de administración, propuestas por la FCSF, o por los centros mismos. Pueden ser desarrolladas por cooperativas de educación popular o por empleados/as de las federaciones o centros.

7. Se ha preferido guardar el anonimato de los centros donde se realizó el trabajo de campo, por lo que los nombres de los mismos son ficticios. 
8. En el marco de las políticas familiares, existe una convención marco a nivel nacional por la cual el papel social de los centros en el territorio está reconocido por el Estado, y convenciones locales que permiten la financiación de la "animación general". Los fondos de las CAF constituyen la mayor parte del presupuesto de los centros sociales.

9. Particularmente en el contexto ya mencionado, de una limitada "tradición" política, muchos/ as miembros de los consejos de administración ocupan ese lugar a partir de un tipo de "intercambio de dones": luego de aprovechar por algunos años las actividades propuestas por su centro social, aceptan participar más como forma de agradecer al centro que por el hecho de tener convicciones políticas o sociales claras.

10. La noción vernácula de "portage politique" significa que la dirección política del proyecto del centro social debe ser asumida por los socios del CA. Es decir, que el sentido del proyecto, sus objetivos de transformación social, deben ser asumidos por ellos/as, mientras que su puesta en práctica es la tarea de los y las empleados/as.

11. Como muchos directores $y$ empleados/as, ellos/as temen "herir" a los representantes elegidos si toman posiciones que podrían interpretarse como demasiado "subversivas" o radicales; como decía uno de ellos: "tal vez sería mejor hablar de participación en lugar de poder de actuar [...] para que los elegidos no se representen al centro social como un enemigo" (Albert, reunión del CA, Centro social del Bosque Rojo, febrero 2013).
Si las formaciones que organizó María pueden situarse claramente en el référentiel de la individuación, insistiendo sobre la realización personal y la progresiva adquisición de competencias individuales como requisito a priori del poder de actuar, es importante notar que este tipo de formación convive con otras claramente ancladas en el référentiel del equilibrio conflictual (que valorizan una visión colectiva de la transformación social) sin ninguna discusión, como fue posible observar en la organización de otra formación en el mismo centro social algunos meses después. Si bien los formadores que trabajaron en una cooperativa de educación popular insistieron en el hecho de que el propósito del "poder de actuar" no fue la realización y el bienestar personal sino la transformación social, en muchas conversaciones informales durante la sesión de formación se hablaba principalmente de los primeros.

El hecho de que coexistan varias concepciones del poder de actuar no resulta sorprendente. Lo que en cambio plantea interrogantes es, por un lado, que la referencia a tal diversidad de visiones siempre se haga utilizando el mismo concepto (poder de actuar), como si pertenecieran a una lógica similar. Y por otro lado, que esta diversidad misma no constituya objeto de debate: las diferencias entre ellas no quedan aclaradas en función de que los actores puedan elegir con pleno conocimiento de causa la versión que prefieren.

Aparte de los/las empleados/as, otro público de las formaciones son los/las socios de los consejos de administración que gestionan los centros sociales. Ellos/as tienen un rol legal como empleadores, pero son también los y las que deben garantizar, según el termino vernáculo, "llevar a cabo" el proyecto social de los centros. Cada uno de los centros sociales elabora (con la participación de los/las habitantes) un "proyecto social", que constituye la trama de sus acciones por un período de cuatro años, que establece el fundamento del reconocimiento como centro social por parte de las Cajas de Asignaciones Familiares (CAF).$^{8}$ Este proyecto social debe ser "llevado a cabo" políticamente frente a las instituciones públicas, los/as representantes elegidos/as locales y los habitantes. Fomentar y sostener la capacidad colectiva de defender en el espacio público valores e impulsar tomas de posición sobre las necesidades y aspiraciones de los habitantes por parte de los socios de los consejos de administración constituye un desafío importante en la estrategia de desarrollo del poder de actuar. ${ }^{9}$

En 2014, en el mencionado centro social, el objetivo de DPA fue presentado a los miembros del CA, entre otras cosas, para que fueran conscientes de sus efectos potenciales sobre las relaciones con las instituciones públicas. De hecho, el centro social había acompañado la movilización de habitantes contra el aumento de los gastos de funcionamiento en viviendas sociales gestionadas por la municipalidad, y se trataba de entender que eso podría modificar las relaciones de colaboración entre la municipalidad y el centro social. La dirección del centro social quería que el CA asumiera la "conducción política" ("portage politique") ${ }^{10}$ de esta iniciativa, aunque la gran mayoría de sus socios/as no tenían ninguna concepción de su papel político o del hecho de que el centro social podía ser un espacio de (apoyo a la) movilización colectiva. Si bien no se opusieron a acompañar a los/las habitantes, algunos/as subrayaron que era necesario que la movilización se hiciera sin "malas intenciones" (es decir, sin que la interpelación de la municipalidad fuera demasiado "firme") y expresaron preocupación de que "después, la municipalidad pueda culpar al centro social por sostener la movilización" (Reunión del Consejo de Administración, Centro Social del Bosque Rojo, febrero, 2013) y reducir su financiación. ${ }^{11}$

Algunas formaciones organizadas a nivel regional tenían precisamente el objetivo de modificar las relaciones con los representantes elegidos y reafirmar el papel verdaderamente político de los socios de CA. En marzo de 2017, la Federación Nacional propuso una formación llamada “¡Anímense a una comunicación política!”. El formador 
de la (FCSF) dijo a los participantes: "hay gente que empieza a reírse cuando ustedes dicen 'poder de actuar,' y sugirió usar otra palabra para que sea más fácil. Pero no hay que ceder nada, ese es vuestro proyecto" (Notas de observación, formación FCSF, marzo 2017). También hizo hincapié en el hecho de que tienen que asumir su legitimidad que es igual que la de otros/as elegidos/as. ${ }^{12}$ Su idea fue, por un lado, insistir sobre la diferencia entre la "conducción política" del proyecto por parte de los socios de CA y la implementación de este por parte de los empleados/as de los centros sociales; y por otro lado, subrayar que, como elegidos/as, ellos/as no tenían que considerarse inferiores a otros/as elegidos/as: "como elegidos del CA, ustedes son tan legítimos como otros elegidos, no tienen que dudar. En lugar de encontrar a los representantes municipales elegidos con reclamos y solicitudes, hay que encontrarlos explicando todo lo que los centros sociales están haciendo" (Formador FCSF, notas de observación, formación FCSF, marzo 2017). El ejemplo que usó fue el del apoyo escolar:

hay que decir a los representantes que los centros sociales son la primera red de apoyo escolar en Francia. Si no los apoyan más, este trabajo será realizado por Acadomia [empresa privada de apoyo escolar] y solo los ricos podrán permitirse pagar por eso. (Formador FCSF, notas de observación, formación FCSF, marzo 2017)

Tal argumentación tiene dos objetivos: subrayar la capacidad de los Centros Sociales de prestar servicios útiles para la población; pero también destacar la dimensión propiamente política de tales servicios al oponer un apoyo escolar accesible a todos a servicios de pago, que refuerzan las desigualdades sociales. Convencer a los socios de CA de su legitimidad y dignidad con respecto a los/as representantes elegidos/as puede ser entendido como una forma de politización si la consideramos como "una autoestima reconquistada en sus capacidades propias de juzgar/enjuiciar, es decir, como cuestionamiento de la convicción de indignidad tan profundamente arraigada en la propia imagen de las clases populares" (Schwartz, 1991, p. 82). Podemos hablar, entonces, de un trabajo de politización que se desarrolla en estas formaciones, a partir de la reconquista de una autoestima colectiva y de la formulación pública de un objetivo de igualdad social.

\section{Desarrollar el poder de actuar: concepciones sobre los/las habi- tantes y la conflictividad}

Hemos visto como varias concepciones sobre el "poder de actuar" circulan sin dar lugar concretamente a formas de explicitación de sus sentidos, a veces no solo de manera diferente, sino como opuestas. Hemos observado también que el proyecto de desarrollar este poder confronta con representaciones poco politizadas y con actitudes de deferencia en cuanto a las autoridades locales. Pero esta estrategia también actualiza tensiones acerca de los vínculos entre los/as empleados/as de los centros sociales y los/ as habitantes, aunque con variaciones importantes según la "versión" del "poder de actuar" elegida. Si se trata de su versión de "educación popular radical", presupone escuchar a los/as habitantes y acompañarlos/as en la elaboración de su propia organización colectiva, en lugar de proponer actividades "llave en mano", a partir de lo que los/las empleados/as consideran como "mejor para ellos/as". Según un responsable de capacitación formado en esta corriente de la educación popular que trabaja regularmente con centros sociales, se trata entonces de "tomar tiempo"; de aceptar ensayos y de no controlar todo, y de dar "prioridad a situaciones que permiten investigar lo que quiere y sabe la gente que encontramos" (Matières Prises, 2015, p. 7). Tal posición a menudo choca con las costumbres adquiridas en los recorridos profesionales del trabajo social.

De hecho, lo que se encuentra frecuentemente es una concepción propedéutica y pedagógica de la participación, según la cual hay que "guiar" a los/as habitantes, percibidos/as
12. Hace referencia al hecho de que los/las socios/as de CA son elegidos/as por los/las habitantes usuarios del centro social. Tienen entonces una legitimidad equivalente a la de las personas elegidas en un consejo municipal, por ejemplo. 
13. Estas Jornadas (Journées professionnelles de l'animation globale [JPAG, Jornadas Profesionales de la Animación global en castellano]) son organizadas cada dos años por parte de la FCSF. Desde hace algún tiempo, jornadas similares están siendo organizadas por socios de los consejos de administración federales de la red. a priori como desprovistos de competencias y capacidades. Como decía una participante en una formación de voluntarios en 2015: "en algún momento, tomas la mano de un niño y después lo dejas" (Daniela, notas de observación, formación regional, febrero 2015). En observaciones propias de varios espacios de formación en la Región Centre Val de Loire, se replicaban muchos comentarios donde se remarcaba que "nuestros [sic] voluntarios no están listos" o que "los habitantes quieren preparar el carnaval y no se interesan en otra cosa" (Notas de observación, formación regional, febrero, 2015). Se puede observar entonces una visión "desde arriba" de los habitantes, que a menudo muestra poca confianza en sus capacidades. En otra formación, alguien habló de la evolución de voluntarios/as, y se evocó la transición de "voluntarios que ayudan y reciben ayuda" hacia voluntarios que "piensan el mundo" (Notas de observación, formación regional, febrero, 2015). La representación implícita es la de los voluntarios/as como incapaces a priori de "pensar el mundo", una visión demasiado "evolucionista" y poco adaptada al objetivo del poder de actuar.

Muchas formas de resistencia se expresan en las formaciones que describen los cambios necesarios en la posición de los empleados/as y socios/as de CA. En un taller organizado durante las jornadas nacionales de intercambio de los empleados/as de centros sociales, ${ }^{13}$ fue presentado el trabajo de un centro social de la Región Poitou-Charentes frente a la movilización de habitantes sobre la concepción de una residencia intergeneracional. El director del centro social explicó la actitud de los y las empleados/as: respetar el compromiso de los/las habitantes, dejarlos/as hacer su propia investigación en el barrio y construir confianza progresivamente, dejándoles controlar la movilización y el proyecto. Durante la observación de las discusiones después de la presentación de esta iniciativa, en mi cuaderno de campo:

El relato de la experiencia insiste sobre la necesidad de dejar a los/as habitantes controlar su movilización, adoptando una posición de disponibilidad frente a sus demandas más que una posición de control o de guía. Lo que muchos/as en el taller traducen como 'pusilanimidad'. (Nota de campo personal, JPAG 2014, Dijon, noviembre 2014)

En otra parte del relato, el ponente menciona tensiones que surgieron entre el colectivo de habitantes y el centro social. Su presidente decidió realizar un "ritual" (sic) para calmar las cosas: él visitó a la presidenta de la asociación de vecinos/as y discutió durante mucho tiempo con ella, de manera que la confianza y la cooperación se reconstruyeron. Una vez más, los/las participantes del taller comentaron con desaprobación este relato; consideraron que esta visita no había sido necesaria, que realizar este ritual se parecía a una forma de "sumisión" del centro social a la presidenta de la asociación :

la reciprocidad y la igualdad (entre empleados/as del centro social y vecinos/as) parecen ser nociones a profundizar. 'Pusilánime' cuando no impone su dirección, el centro social se 'somete' cuando escucha las demandas de respecto por parte de la presidenta de la asociación de vecinos/as y se compromete a una forma ritualizada de reconocimiento mutuo. (Nota de campo personal,JPAG 2014, Dijon, noviembre 2014)

Tomando un ejemplo que ocurrió en otra región, se pueden observar reacciones similares en la Región Centre Val de Loire. En entrevistas realizadas en el marco de un proyecto colectivo de investigación en curso, ${ }^{14}$ resultaron frecuentes las declaraciones de empleados/as según las cuales ellos/as deben "proteger” a los/as habitantes, escuchando sus deseos y proyectos; aunque los mantienen al mismo tiempo en una posición infantilizadora cuando consideran que desde sus propias competencias tales proyectos no son viables. Un diálogo escuchado durante un taller de trabajo sobre los obstáculos al DPA ilustra claramente esta posición: 
Empleado 1: - ¿se atreven o no a acompañar una voluntad de habitantes en algo que ustedes saben demasiado complicado, arriesgado o perdido de antemano? Empleado 2: - Más vale no hacer [el proyecto] que hacer esperar [a los/las habitantes] a que se pueda realizar. (Notas de observación, encuentro departamental de los centros sociales 37, septiembre 2019).

Si la puesta en circulación del proyecto de desarrollar el poder de actuar cuestiona representaciones ordinarias de los/las habitantes como desprovistos/as de capacidades, también reactiva el tema problemático de la ya mencionada relación con la conflictividad social, reconocido, sin embargo, por gran parte de la literatura como una dimensión central de procesos de politización. En numerosas formaciones, tanto nacionales como locales, fue evocado el valor del conflicto para el DPA:

para desarrollar el poder de actuar hay que cambiar nuestras mentalidades y tener la valentía de redescubrir la confrontación en los centros sociales, hay que ver las cosas que molestan de manera positiva: lo que consolida a un grupo es la discusión y el conflicto, y su resolución. (Notas de observación, intervención de un socio del Colectivo Poder de actuar durante las JPAG de 2014)

Otros encargados de formación recordaron, durante una sesión en la Región Centre Val de Loire desarrollada en el mismo año, las cuatro tareas de la educación popular (concientizar, emancipar, aumentar el poder de actuar y transformar la sociedad) e insistieron sobre la necesidad de poner el conflicto una vez más al centro en lugar de eludirlo.

Pero nuevamente aquí lo que se observa con más frecuencia, en especial en la Región Centre Val de Loire, son formas de evasión de la conflictividad social. No puedo mencionar aquí todos los ejemplos de tal evasión, donde la cuestión de la discriminación ocupa un lugar importante. Solo voy a hacer referencia al caso de un encuentro que tuvo lugar en un CS de la Región Centre Val de Loire pocos días después de los ataques de noviembre 2015. ${ }^{15}$ Como cada jueves, se celebró un encuentro llamado "El jueves pienso" 16 con el tema (elegido antes de los ataques): "El miedo del Otro". Unas 50 personas se reunieron, mujeres y hombres de edad y origen diverso: mujeres jóvenes con un velo en la cabeza, recientes jubilados blancos, todos/as estaban conmovidos/as y emocionados/as. Muy rápidamente "el Otro" fue nombrado: "estábamos aquí para hablar del miedo del Otro y no pasó mucho tiempo antes de que el otro se nombrara como 'el musulmán'. Esta pregunta nos separa” (Jubilada blanca, notas de observación, Centro social de la Ruta, noviembre 2015). Los puntos de vista, en el sentido propio de las localizaciones en el mundo social desde los cuales entendemos la sociedad, fueron varios. Muchos intercambios indicaron la politicidad de los/las participantes que mencionaron el contexto internacional o estigmatizaciones en el espacio público y se refirieron a las teorías de la conspiración, o usaron la palabra "francés" (eufemismo para "blancos") como lo contrario de "las otras etnias", aunque la gran mayoría de los/las participantes eran franceses. $\mathrm{O}$, como decía una mujer blanca:

Estamos hablando de lo que nos separa. ¿Por qué no podemos retomar el control y hablar de lo que nos reúne? Todos aquí somos ciudadanos. 'Libertad, igualdad, fraternidad', está escrito en lo alto de los edificios, para ver estas palabras hay que levantar la cabeza, y esto no es poca cosa. Hay que elevarse sobre nuestras particularidades. Debemos vivir juntos como ciudadanos [en referencia a una mujer con un velo], vuestro velo me molesta, pero si podemos hablar de lo que nos reúne, estaremos menos preocupados. (Jubilada blanca, notas de observación, Centro social de la Ruta, diciembre 2015)

Las expresiones de politicidad fueron entonces numerosas, y podrían haber sido usadas como puntos de apoyo en pos de un trabajo de "politización" de los debates, de
15. El 13 de noviembre 2015 en París, 131 personas fueron asesinadas $y$ más de 400 heridas en una sala de conciertos y en las terrazas de cafés por terroristas de Daesh.

16. Juego de palabras en francés: "jeudi je pense" que al escucharlo se puede también entender como "digo, pienso". 
17. El "cruce de saberes" es una experimentación conducida por ATD Quart Monde, una Organización de la Sociedad Civil que trabaja con personas en situación de gran pobreza, a nivel nacional e internacional, para mejorar las políticas públicas de atención a estas poblaciones y destacar las "dimensiones ocultas" de la pobreza. Los saberes que se "cruzan" son los de las personas pobres, de los/las empleados/as que trabajan con ellos/as y de investigadores.

Véase Groupes de recherches Quart Monde-Université (2008). explicitación de los puntos de vista y experiencias, al incluir los conflictos y las formas de entendimiento de los desafíos contemporáneos de la sociedad en Francia. Pero para la trabajadora social que organizaba los encuentros del jueves bastaba con que la gente hablara, sin ningún otro objetivo más que un fin catártico y terapéutico. Si bien, por supuesto, tal actitud tiene que ver con su personalidad y con la concepción de su trabajo, traduce también una tensión más general en los centros sociales de la Región Centre Val de Loire: la de un tratamiento individualizado y psicológico de lo social en lugar de una concepción que incluya un objetivo de transformación social y de consideración de la conflictividad social. Tal tratamiento hace casi imposible aprovechar expresiones de politicidad entre los/las habitantes para politizar los discursos, prácticas y actores.

\section{Conclusión}

Estas observaciones y análisis nos incitan a reflexionar sobre cómo se puede "aprender" a desarrollar el "poder de actuar". En general, tal aprendizaje está concebido según las rutinas clásicas de la formación, es decir, a partir de un enfoque, si no teorético, en todo caso abstracto. Sin duda, parece necesario aclarar las diversas "versiones" del "poder de actuar" y sus dimensiones políticas, especialmente entre la emancipación del individuo aislado o en las formas colectivas de emancipación. Pero en un contexto poco politizado, y donde domina una "cultura profesional" y visiones de la sociedad respaldadas por un enfoque individualizador, cabe preguntarse si este tipo de formación teórica, en lugar de concientizar políticamente a los actores, termina más bien por reforzar las aproximaciones despolitizadas del référentiel de la individuación, en el cual el papel de los centros sociales con respecto a la formación de sujetos políticos consiste en estimular y organizar la solidaridad humana entre individuos a partir de relatos de reconocimiento y oportunidades. El tema entonces podría ser el de concebir formaciones que, más allá de proponer herramientas "técnicas", proporcionarían también la posibilidad de formarse políticamente, es decir, de adquirir instrumentos de análisis de las desigualdades e injusticias sociales contemporáneas que podrían, por ejemplo, permitir reconocer las formas existentes de politicidad en los barrios populares. La descripción anterior del encuentro sobre los ataques muestra cómo los "ciudadanos pueden apoyarse en ocasiones en su experiencia personal para entender razonamientos políticos complejos" (Talpin, 2010, p.95), y destaca una "forma mínima de politización" que la empleada responsable no aprovecha. Discriminaciones, desigualdad social, contexto internacional, igualdad entre los/as ciudadanos/as a pesar de sus particularidades; ninguna de estas expresiones de politicidad fueron recuperadas por ella como "palanca" de concientización, de atención a las formas de conflictividad social en el barrio. Esta orientación podría ser aún más útil ya que, tradicionalmente, en el trabajo social, la formación se ve como una manera de adquirir una "caja de herramientas" sin que se refleje en un cuestionamiento fundamental de las prácticas o posiciones establecidas, por ejemplo con respecto a las representaciones de los/las habitantes y de sus competencias.

Mis observaciones, de hecho, muestran que tales cambios (especialmente en la capacidad de escuchar a los/las habitantes y acompañar a sus dinámicas colectivas) se realizan más a partir de la experimentación práctica que de la transmisión de discursos, relatos o herramientas técnicas. Todos/as los/as empleados/as de centros sociales que conocieron la práctica del "cruce de saberes" elaborada por Agir tous pour la dignité, (ATD por su nominación en frances, traducido como "actuar todos por la dignidad") Quart Monde ${ }^{17}$ dicen que han vivido una "ruptura" o una "epifanía" que les permite un cambio radical en la concepción de sus roles y de los/las habitantes. Tal efecto de ruptura resulta del hecho de que el cruce de saberes supone la "igualdad de las inteligencias" (Rancière, 1987) y de los saberes. Este fue el caso, por ejemplo, de algunos/as empleados/as del centro social que mencioné previamente, cuyo acompañamiento de una iniciativa de habitantes fue descrito durante un taller en las JPAG. Las reacciones que describí tradujeron el miedo de muchos/as a perder poder y control. 
Para numerosos/as empleado/as, admitir tal igualdad puede ser interpretado como un cuestionamiento fundamental de sus competencias profesionales. Pero este miedo puede encontrarse asimismo en los/las voluntarios/as que tienen una posición más militante que la media; quienes pueden considerar también que sus "competencias políticas" están siendo cuestionadas, ya que la convicción tradicional respecto de ellos/ as es que "saben mejor" que las clases populares cuál es "el camino bueno", y que su papel es enseñarlo, o más precisamente "guiarlas".

A nivel más general, esta primera aproximación desde espacios de capacitación en centros sociales subraya la necesidad de reflexionar más profundamente en relación con la pregunta sobre la formación en una época de la "democracia del hacer"18 (Pruvost, 2019). De hecho, el desafío de una formación destinada a politizar (los actores, las prácticas, los discursos) está estrechamente vinculado con las transformaciones contemporáneas de la democracia. ¿Qué quiere decir "formar" cuando se desarrollan formas democráticas que se basan más en las prácticas, en el "hacer juntos/as" (Fernández Álvarez, 2016), que en la "formación de la opinión"? Por cierto, existieron "pedagogías de la emancipación" que se basaban en la práctica, y ellas también estaban atravesadas por una tensión entre lo disciplinar y la emancipación, una tensión constitutiva de los procesos de ciudadanía (Neveu, 2013). Sin embargo, cuando las formas mismas de las aspiraciones de democratización se concretizan más por el hacer que por el aprender de saberes abstractos, sin duda hay que repensar las acciones de formación.

Como en todos los espacios que tienen el objetivo de desarrollar la participación o el poder de actuar, uno de los principales riesgos de la red de los centros sociales es utilizar el concepto de "poder de actuar" sin cambiar realmente las prácticas y costumbres, o fetichizar las herramientas para evitar el debate sobre sus dimensiones propiamente políticas y de transformación social. Más allá de las tensiones históricas en la red de los centros sociales en relación con la cuestión de la transformación social que mencioné al inicio, queda abierta una pregunta central sobre las modalidades contemporáneas de la "formación política" de los actores, en una época de "democracia del hacer". Sin duda, esto requiere prestar más atención a las formas "ordinarias" de politicidad que se expresan en momentos y prácticas que muchas veces los diferentes actores, incluyendo los y las investigadores/as, no consideran como "lugares de lo político".

\section{Agradecimientos}

La autora quiere agradecer a la Dra. María Inés Fernández Álvarez por su inestimable ayuda en la corrección lingüística del artículo.

\section{Sobre la Autora}

Catherine Neveu es doctora y Habilitation à diriger des Recherches (Habilitación a dirigir Investigaciones, el diploma superior al doctorado PhD) en Antropología, miembro del IIAC (Instituto Interdisciplinario de Antropología del Contemporáneo, Centre National de la Recherche Scientifique de Ecole des Hautes Études en Sciences Sociales [CNRS-EHESS] París). Desarrolla desde hace varios años un enfoque antropológico sobre procesos de ciudadanía, y se dedica en este momento a una investigación sobre estrategias de empoderamiento en centros sociales.

\section{Nota de los Editores}

Artículo elaborado especialmente para Cuadernos de Antropología Social a partir de la conferencia de la autora en el Instituto de Ciencias Antropológicas. Noviembre de 2018. Buenos Aires, Facultad de Filosofía y Letras, Universidad de Buenos Aires.
18. Según Pruvost, una de las transformaciones contemporáneas importantes de las formas democráticas es el desplazamiento del actuar democrático del logos (la ágora) hacia prácticas cotidianas, ordinarias, basadas en el "hacer". Luego de analizar una diversidad de iniciativas alternativas y ecológicas, subraya cómo "lo político" puede encontrarse en "acciones triviales" (tales como la creación de letrinas aboneras, de una cantina autogestionada con precios libres, o la colaboración en una obra participativa). Habla entonces de la "politización del gesto alguno" de la democracia como una experiencia constante, repetida y vivida a escala de la vida cotidiana, que se diferencia de un pensamiento de la democracia exclusivamente como una forma de gobierno. Véase Pruvost (2019). 


\section{Q Referencias bibliográficas}

》Arnaud, L. y Guionnet, C. (2005). Les frontières du politique. Enquête sur les processus de politisation et de dépolitisation. Rennes: Presses Universitaires de Rennes.

» Bacqué, M.-H. y Biewener, C. (2013). L'empowerment, une pratique émancipatrice? París: La Découverte.

» Carrel, M. (2017). Expériences de discriminations et politisations émergentes. Enquête à Villepinte et Montréal-Nord. Tesis de HDR "Habilitation à diriger des recherches"- Habilitación a dirigir investigaciones. Universidad de París, París. Francia..

» Cortesero, R. (2013). Les centres sociaux, entre participation et cohésion sociale. Dossiers d'étude 160. París: Caisse Nationale des Allocations Familiales.

»Dessertine, D., Durand, R., Eloy, J., Gardet, M., Marec, Y., y Tétard, F. (2004). Les centres sociaux 1880-1980. Une résolution locale de la question sociale? Lille: Presses Universitaires du Septentrion.

»Durand, R. (1996). Histoire des centres sociaux, du voisinage à la citoyenneté. París: La Découverte.

"Federación Nacional de los Centros Sociales. (2012). Ecouter, comprendre, agir, París: Federación Nacional de los Centros Sociales.

» Federación Nacional de los Centros Sociales. (2014). La fabrique des posibles. Projet fédéral 2014-2022. París: Federación Nacional de los Centros Sociales.

» Fernández Álvarez, M. I. (Ed.) (2016). Hacer junt@s: dinámicas, contornos y relieves de la política colectiva. Buenos Aires: Biblos.

»Groupes de recherches Quart Monde-Université (2008). Le croisement des savoirs et des pratiques. Quand des personnes en situation de pauvreté, des universitaires et des professionnels pensent et se forment ensemble. París: Editions du Quart Monde-Editions de l'Atelier.

» Guionnet, C. (2013). Les analyses socio-historiques de la politisation en France (19ème siècle). En S. Marton y C. Vintila-Ghistulescu (Eds.), Penser le 19 ème siècle. Nouveaux chantiers de recherche (pp. 25-72). Bucarest: Editions universitaires Alexandru loan Cuza lasi.

" Hamidi, C. (2006). Eléments pour une approche interactionniste de la politisation. Engagement associatif et rapport au politique dans des associations locales issues de l'immigration. Revue Française de Science politique, 56(1), 5-25.

» Lagroye, J. (2003). La politisation. París: Belin.

" Maguin, P. (2004). Une histoire des centres sociaux en France. París: Mémoires VivesCentres sociaux.

» Marcus, G. E. (1995). Ethnography in/of the World System: The Emergence of Multi-Sited Ethnography. Annual Review of Anthropology, 24, 95-117.

» Matières Prises (2015). Vers un pouvoir d'agir. Synthèse de la formation à destination de bénévoles et salariés des centres sociaux. Recuperado de http://www.sanstransition. org/wp-content/uploads/Vers-un-pouvoir-dagir-synth\%C3\%A8se-ultime.pdf.

» Mémoires Vives (2016) Brèves histoires des Centres sociaux. Recuperado de http://memoiresvives.centres-sociaux.fr/histoire/histoires-de-centres-sociaux/. 
" Merklen, D. (2006). Une nouvelle politicité pour les classes populaires. Les piqueteros en Argentine. Tumultes, 2(27), 173-197.

" Merklen, D. (2012). Individus populaires. Sociabilité et politicité. En R. Castel y C. Martin (Eds.), Changements et pensées du changement (pp. 100-120). París: La Découverte.

》Muller, P. (2013). Les politiques publiques. París: Presses Universitaires de France.

"Neveu, C. (2013). “E pur si muove!”, ou comment saisir empiriquement les processos de citoyenneté. Politix, 26(103), 205-222.

» Neveu, C. (2016). Un projet d'émancipation à l'épreuve de sa mise en pratique. Revue du MAUSS, 48, 163-176.

»Pruvost, G. (2019). La démocratie du faire, En GIS Démocratie et participation (Ed.), Expérimentations démocratiques. Pratiques, institutions, savoirs. Lille: Editions du Septention, (En Prensa).

" Rancière, J. (1987). Le maître ignorant. Cinq leçons sur l'émancipation intellectuelle. París: Fayard.

» Schwartz, O. (1991). Sur le rapport des ouvriers du Nord à la politique. Matériaux lacunaires. Politix, 4(13), 79-86.

" Talpin, J. (2010). Ces moments qui façonnent les hommes. Eléments pour une aproche pragmatiste de la compétence civique. Revue Française de Science politique, 60, 91-115. 
